\title{
Effective teaching strategies to encourage learning behaviour
}

\author{
${ }^{1}$ Mohd Mahzan Awang, ${ }^{1}$ Abdul Razaq Ahmad, ${ }^{1}$ Jamalul Lail Abdul Wahab, \\ ${ }^{2}$ Nordin Mamat \\ 1. (Faculty of Education, The National University of Malaysia, Malaysia) \\ ${ }^{2}$ (Faculty of Education and Human Development, Sultan Idris Education University, Malaysia)
}

\begin{abstract}
Getting pupils' attention as a way to engage them in learning activities poses a challenge to teacher. Various strategies have been used to make their learning effective. Based on these issues, this study was carried out to investigate the ways strategies are used by a teacher in encouraging pupil learning behaviour. Five teaching strategies were identified and observed in this study: encouragement, praising, guidance, positive reinforcement and ignorance. The first ten minutes (induction-set phase) of three lessons organised by one female teacher were digitally recorded and independently analysed. Data analysis focuses on the effect of teaching strategies towards pupil learning behaviour. Learning behaviour observed includes pupils' participation in lesson activities, proactive action initiated by pupils, answering a question and facilitating group works. Overall results suggest that the effectiveness of induction-set is dependent on teacher's creativity and pedagogical content knowledge. As one strategy does not fit all situations, it is vital for the teacher to initiate creative lesson plans to attract pupils' attention. Results also suggest that the display of positive actions toward disruptive behaviour as well as the lack of praises given to pupils increased problematic behaviour in classroom. This study provides insight to effective teaching practice for promoting learning behaviour in classroom contexts. Implications towards teaching practices are discussed.
\end{abstract}

Keywords - effective teaching, encouragement, learning behaviour, lesson transition, teaching strategies

\section{INTRODUCTION}

Getting pupils' attention at the beginning of the lesson is vital as pupils need to be physically, emotionally and mentally ready before engaging in the lesson (Lim, 2005). In this paper the term induction-set is used to refer to strategies used by a teacher to gain pupils attention at the beginning of the lesson. Good setinduction is essential as it motivates pupils in lesson activities, simultaneously making the teaching and learning process interesting and meaningful (James \& Coolier, 2011). Although many teaching strategies were suggested in the past, no one can claim that one approach is better than the others. This is because the effectiveness of teaching strategies is dependent on many factors including teacher's capability (Siwatu, Frazier, Osaghae, \& Starker, 2011), teachers knowledge on pupils background (Allen, Taleni, \& Robertson, 2009), teacher's pedagogical content knowledge (Park \& Oliver, 2008; Shulman, 1987), class size (Gottfredson \& DiPietro, 2011), and classroom management practice (Daniels, 2009; Hue, 2007; Weiner, 2010). Indeed, most of the strategies suggested are more likely to focus on the whole-process of the teaching and learning instead of looking at the use of set-induction in teaching and learning. Due to this limitation, the current study investigated strategies used by teachers during induction-set and how it might be able to promote learning behaviour among pupils.

\section{Teaching Strategies}

Results of past studies on teaching approaches indicated that are many strategies can be used for promoting learning behaviour. The most common strategies suggested are communication approach, behaviour modification models and whole-school approach. Communication approach sees that inter-personal relationships are the core element for promoting learning behaviour as pupils feel happy to communicate with others. Basic principles of this approach are that "learning occurs through communication and it is facilitated when pupils responsibly participated in learning process (Martin \& Sugarman, 1993, p. 16)". This approach also emphasises the importance of teachers' professionalism such as responding to pupils query in productive ways and also listen sensitively to pupils' voice.

Behaviour modification model focuses on intervention programmes. A study of the implementation of the Bully Prevention-Positive Behaviour Support programme carried out by Ross and Horner (2009) can be categorised as one of the Behaviour modification programmes. Another study found that behaviour modification programme, namely the Check in/Checkout (CICO), was effective in "reducing number of office discipline referrals for pupils who entered the programme (Filter, McKenna, Benedict, Horner, \& Todd, 2007, p. 69)". 
Although extensive research has been carried out in the past with a focus on the effectiveness of behaviour modification programmes (Dunlap, Carr, Horner, Zarcone, \& Schwartz, 2008; Fabiano et al., 2007), and most of the studies have provided evidence supporting the effectiveness of the strategies, it does not mean that professionals and pupils are contented with such programmes. This is because behaviour modification programme requires professional training, expertise, and full commitment from a school community. In fact, there are many internal distractions which may affect the effectiveness of any behaviour modification programmes. Previous research revealed that in carrying out behaviour modification programmes, teachers had faced several challenges including time constrains, availability of resources to teachers, getting family collaboration and collaboration with other staff (Chitiyo \& Wheeler, 2009). This informs us that practical teaching strategies are essential.

Whole-school approach posits that teachers' satisfaction and pupils' happiness solve most behavioural problems in school (Rogers, 2007). This approach emphasises the importance of the following elements: values, rights and rules and responsibilities, and their relationship to the needs of individuals. It has three levels of strategies that are institutional or whole-school level, group level, and individual level. Institutional level focuses at the school ethos where the general expectation of pupils' behaviour is clearly stated in the school behaviour management policy. This includes supervisory system, response system to negative behaviour, sanctions, rewards and the referral system. School ethos can be positive or negative. At a group level, teachers with good teaching skills are essential. Effective teaching requires knowledge in subject-matters and teaching skills (Pedagogical Content Knowledge). Individual level focuses on a special technique for disruptive pupils who often pose a challenge to teachers. This includes individual counselling and a one-to-one communication. Olweus (2003) suggested several strategies that can be used by teachers to prevent negative behaviour at individual level such as serious talks with pupils involved, support for parents, and discussion groups among parents of all children involved. Individual level focuses on the treatment of pupils who display problematic behaviour. This includes parental engagement in helping pupils to improve their behaviour.

Although many teaching strategies were suggested in the past, is the ways in which teachers implement these strategies are still unclear. There is a limitation in previous studies as researchers have not investigated in much detail on the effect of teaching strategies during the induction set as much focus was given to the whole teaching and learning process. Therefore, the current study was set to examine the effectiveness of teaching strategies in promoting learning behavior and investigate strategies used by teachers in response to disruptive behaviour during the induction set.

\section{LESSON TRANSITION}

In a system where pupils learn several academic subjects per day, a proper planning of lesson transition plays an integral role as it determines the smoothness of the teaching process (Beskeni, Yousuf, Awang, \& Ranjha, 2011). Malaysia is one of the countries that practice that kind of education system. As such, the teachers in Malaysia are educated to specialize in a specific academic subject at the teachers' training college. At school, according to the daily schedules of subjects taught, the teachers move from one classroom to another while pupils remained in their respective classrooms. After one lesson is finished, another teacher will go into the classroom to start teaching a different academic lesson. This means that both teachers and pupils are facing challenges of lesson transition. For the teachers, getting pupils' attention at the beginning of the lesson requires specific skills and knowledge. They have to ensure that the pupils are ready for lesson activities. Past studies show that getting pupils' attention, engaging them in lesson and managing pupil behavior are the most challenging tasks for teachers (Awang, 2012; Smolnisky, 2009). As pupils are diversed in terms of their skills, ability and knowledge, getting prepared for learning requires different stimulus and strategies. This scenario describes the importance of the management of lesson transition which is called as 'induction set' in this study.

\section{RESEARCH METHODOLOGY}

A case study approach was employed in this study to allow observation to be carried out during three lessons organised by one female teacher in a multi-ethnic school. The teacher (female, Malay, aged 39) has taught in both primary and secondary schools for more than 10 years. During the observation, she had just finished professional training in education. Thus, she might have fresh knowledge on classroom management and skills in managing lesson activities effectively. Pupils in the classroom observed were moderate academic achievers. In most public schools in Malaysia, pupils are streamed based on their academic attainment (Nor et al., 2007).

The data collected via the sessions was recorded on a digital video recorder for the purpose of analysis. Interval recording technique was used to record the occurrence of the target behaviour. Interval recording refers to a technique in which the observer indicates (again using check marks) whether the target behaviours occur during a specific time interval. Interval length varies depending on the frequency of the behaviour, the amount 
of time allowed for the observation, and the skill of the observer in monitoring and recording child behaviour. (Nock \& Kurtz, 2005, p. 365)

The focus was given to the teacher's action and the behaviour of the majority of pupils in the classroom. Target behaviours observed in this study were strategies used by teachers to encourage learning behaviour, pupils' behaviour and teacher's response to inappropriate behaviour. Pupil's behaviour observed including disruptive behaviour (responding negatively to teacher's instruction/questions and disturbing other pupils such as discussing irrelevant matters with their friends), attentive behaviour (responding positively to teacher's instruction/questions), initiating learning (asking the teacher a question, helping the teacher and friends in doing the given task) and uninvolved behaviour.

Teaching approaches observed in this study were strategies to encourage pupils to be involved in 'induction set' phase activities (such as asking pupils to do some activities and actions to elicit pupils' attention), praising, and guidance (guiding pupils to complete the task given). Also included in the observation are positive and negative strategies used by the teacher in responding to the pupils' negative behaviour. In this study, positive strategies refer to supportive and helpful approaches including listening to pupils, looking at the pupil who interrupted the lesson and engaged other pupils to listen to him/her, and praising pupils. On the other hand, negative strategies refer to ignorance and 'hard' approaches such as shouting at pupils, hitting objects or pupils, and calling a pupil with a bad name. This observational data was analysed using the structured school observation coding system (Nock \& Kurtz, 2005). Coding activities were independently carried out using two coders. Inter-rater reliability scores $(83 \%)$ show that both coders have high agreement.

\section{RESULTS AND DISCUSSION}

Overall results indicate that teachers used many strategies to attract pupil's attention at the beginning of the lesson. The most often ones were questioning pupils about current issues, and stimulating pupils to engage in the question-answer activities. The teacher also used a 'card game' to prepare pupils for the lesson. The use of various strategies is seen to be effective as many pupils engaged in the activities organised. Teacher's initiative and creativity are found to be the core elements in making the transition time smooth and effective. Data from this study has contributed to the existing knowledge on pedagogical content knowledge (Park \& Oliver, 2008; Shulman, 1987) as this study suggests that having pedagogical skills and content knowledge is not enough as effective teaching requires teacher's creativity based on the situation in classroom.

Results from the first observation revealed that the teacher (Subject Teacher CS1, female, Malay, aged 39 years) used problem-based solving approach in teaching the Malay language. The pupils in the class (31 pupils attended the lesson) were asked to find and suggest the correct answer for texts containing several grammatical mistakes. As one Chinese pupil (girl, aged 14 years) in the class could not speak and read the Malay language fluently, the teacher provided guidance and gave a less complex text to be analysed. This helped the pupil engage in the lesson organized. The second session was held by the same teacher in the same class. This means that teacher's knowledge of pupils' ability and learning issues are important for effective teaching. This is in-line with previous studies which suggest that teachers' knowledge on pupils' background are essential (Beskeni, et al., 2011).

Table 1 Pupil reaction towards encouragement activities

\begin{tabular}{|c|c|c|c|c|c|c|c|c|c|c|c|c|c|c|c|c|}
\hline \multirow{3}{*}{ Strategies } & \multirow{3}{*}{$\&$ respond type } & \multicolumn{5}{|c|}{ Observed session 1} & \multicolumn{5}{|c|}{ Observed session 2} & \multicolumn{5}{|c|}{ Observed session 3} \\
\hline & & \multicolumn{5}{|c|}{ Minutes } & \multicolumn{5}{|c|}{ Minutes } & \multicolumn{5}{|c|}{ Minutes } \\
\hline & & 1 & 2 & 3 & 4 & 5 & 1 & 2 & 3 & 4 & 5 & 1 & 2 & 3 & 4 & 5 \\
\hline $\begin{array}{l}\text { Teacher } \\
\text { action }\end{array}$ & $\begin{array}{l}\text { Encouragement } \\
\text { activities }\end{array}$ & l & /II// & IIIII/I & //I/ & //I/// & // & /III/ & /// & //II/II// & //// & /I// & /III/ & $/ /$ & /// & I \\
\hline \multirow{4}{*}{$\begin{array}{l}\text { Pupil } \\
\text { behaviour }\end{array}$} & Disruptive & $\mathrm{O}$ & I & $/ / / /$ & $/ / / / / /$ & $\mathrm{O}$ & $/ /$ & $/ /$ & $/ / / / / /$ & $/ /$ & $/ /$ & $\mathrm{O}$ & I & $\mathrm{O}$ & I & I \\
\hline & Uninvolved & $\mathrm{O}$ & $\mathrm{O}$ & III & I/I// & $\mathrm{O}$ & /// & //I & 1 & I & 1 & 1 & 1 & 1 & $\mathrm{O}$ & I \\
\hline & Attentive & 1 & /I/I & 1 & 1 & IIIII & I & $/ /$ & /I/I & // & /I/I & I & IIIII & 1 & 1 & 1 \\
\hline & Initiative & $\mathrm{O}$ & $\mathrm{O}$ & /// & /// & $\mathrm{O}$ & $\mathrm{O}$ & $\mathrm{O}$ & $/ /$ & $\mathrm{O}$ & $\mathrm{O}$ & $/ /$ & $\mathrm{O}$ & $\mathrm{O}$ & // & $\mathrm{O}$ \\
\hline
\end{tabular}

Note: / represents one action shows, O represents no action shows

Table 1 shows that the teacher often used encouragement activities including 'question and answer' and 'guessing the answer activities' in order to get pupils' attention. Disruptive behaviour was increased when the teacher encouraged the pupils to participate in those activities. There was a positive trend observed during the first five minute in the first session between strategies used by the teacher and pupils behaviour. At the beginning of the lesson, the teacher asked the pupils a few questions to elicit the pupils' attention. This questionanswer process took place for five minutes. Although the pupils were behaving in numerous ways, most of them responded to questions posed by the teacher. At the same time, a few pupils disrupted the lessons by talking out of turn. Data collected from the second observation shows that at the beginning of the lesson, majority of the pupils ignored the presence of the teacher in the classroom. Some pupils disrupted their friends. Then, the teacher asked several questions to attract the pupils' attention and also to encourage them to engage in the 
lesson. As a result, inappropriate behaviour was reduced and the pupils started paying attention to the lesson. This situation may be caused by the teacher's action. In the third session in which pupils worked in groups, and were given different problems to be solved, the data revealed that the more encouragements used by the teacher, the higher the participation among pupils. This finding contributes to the searching of effective teaching strategies raised by past researchers (Gotzens, Badia, Genovard, \& Dezcallar, 2010; Smolnisky, 2009). As the teacher provided a constant guidance and encouragement for the pupils, less disruption occurred across the lesson. Overall results from the observations of the three sessions revealed that encouragement activities have an impact towards attentive behaviour among pupils. However, it was also observed that disruptive behaviour still persisted along the last 3 minutes of the lesson. This indicates that although encouragement activities are able to gain the attention of most pupils, it is vital for teachers to demonstrate creativity and initiative in organising classroom activities involving all pupils is vital.

Table 2 Strategies used to reinforce learning behaviour

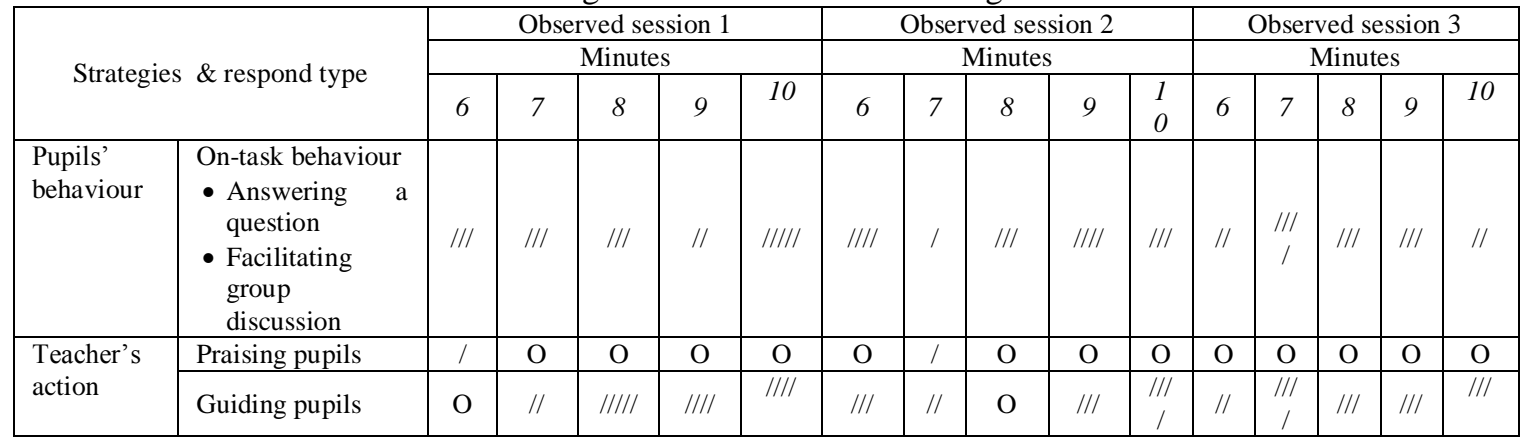

Note: / represents one action shows, O represents no action shows

Table 2 shows that the use of praise is not commonly used during the sessions by the teacher under observation. Praising pupils only occurred twice, each one during the first and second observation. Although many past studies have reported that praising is an effective method to reinforce learning behaviour (Nelson, Young, Young, \& Cox, 2010; Wheatley, West, Charlton, Sanders, \& Taylor, 2009), data from this study shows that praising pupils is hardly ever used. The teacher tended to provide guidance to the pupils who had problems in solving the given task instead of reinforcing the positive behaviour exhibited by the pupils. A possible explanation for this might be that many pupils required guidance during the lesson. It is interesting to note that, however, guidance provided by the teacher increased on-task behaviour, which means that the teacher prioritized guidance when carrying out the lesson to make the teaching and learning effective.

Table 3 Respond to negative behaviour

\begin{tabular}{|c|c|c|c|c|c|c|c|c|c|c|c|c|c|c|c|c|}
\hline \multirow{3}{*}{\multicolumn{2}{|c|}{ Strategies \& respond type }} & \multicolumn{5}{|c|}{ Observed session 1} & \multicolumn{5}{|c|}{ Observed session 2} & \multicolumn{5}{|c|}{ Observed session 3} \\
\hline & & \multicolumn{5}{|c|}{ Minutes } & \multicolumn{5}{|c|}{ Minutes } & \multicolumn{5}{|c|}{ Minutes } \\
\hline & & 6 & 7 & 8 & 9 & 10 & 6 & 7 & 8 & 9 & 10 & 6 & 7 & 8 & 9 & 10 \\
\hline $\begin{array}{l}\text { Pupils' } \\
\text { behaviour }\end{array}$ & $\begin{array}{l}\text { Off-task behaviour } \\
\text { - Talking out-of } \\
\text { turn } \\
\text { - Disrupt other } \\
\text { pupils } \\
\text { - Day-dreaming }\end{array}$ & /II & /II & $\mathrm{O}$ & $\mathrm{O}$ & // & IIIII & III & IIIII & IIIII & /IIII & $\mathrm{O}$ & III & III & l & $\mathrm{O}$ \\
\hline $\begin{array}{l}\text { Teacher's } \\
\text { action }\end{array}$ & $\begin{array}{l}\text { Positive } \\
\text { - Giving } \\
\text { disruptive } \\
\text { pupils } \\
\text { specific task } \\
\text { - Asking } \\
\text { disruptive } \\
\text { pupils } \\
\text { question } \\
\end{array}$ & I & $\mathrm{O}$ & $\mathrm{O}$ & $\mathrm{O}$ & $\mathrm{O}$ & $\mathrm{O}$ & I & $\mathrm{O}$ & $\mathrm{O}$ & $\mathrm{O}$ & $\mathrm{O}$ & $\mathrm{O}$ & $\mathrm{O}$ & $\mathrm{O}$ & $\mathrm{O}$ \\
\hline & Ignore & $\mathrm{O}$ & // & IIIII & IIII & IIII & III & // & $\mathrm{O}$ & III & IIII & // & III & /II & III & /II \\
\hline
\end{tabular}

Note: / represents one action shows, O represents no action shows

Table 3 shows that the use of positive approach such as involving disruptive pupils to complete a task was not a common practise in the sessions observed. Instead, the teacher often ignored inappropriate behaviour. As a result, disruption occurred throughout the lesson in each session observed. This finding suggests that ignorance is not an effective teaching strategy to stop or decrease off-task and disruptive behaviour although it may be suitable to be used in a low-problematic situation. As can be seen in Table 3, off-task behaviour frequently occurred during the second session under observation. In this situation, it is essential for teachers to 
display the ability to make a right decision in carrying out strategic actions in classroom for effective teaching and learning.

\section{CONCLUSION AND RECOMMENDATIONS}

The observation of the three sessions highlights the importance of teacher's initiative, creativity, knowledge on pupils background, pedagogical and management skills for making teaching and learning effective. This is important because pupils behave in various manners. Teachers' ability to identify suitable strategies during the induction-set phase is a valuable skill for strategizing effective teaching. Although praising is not commonly used by the teacher in this study, overall data revealed that she managed to engage pupils in lesson activities. The reason for the lack of positive reinforcement is not clear but it may seem possible that might have a link with cultural background in which giving praises is not part of their cultural practices. However, there is no concrete evidence about the link between socio-cultural elements and the use of praising words as this study has not explored the topic. Therefore, it is significant that more research on this topic is undertaken before the said link is more clearly understood.

The most obvious finding that emerged from this study is that teachers need to realise that their actions influence the behaviour of pupils in classroom; hence teachers must be aware of their actions and strategies in managing the pupils. There is enough evidence from this study and also from previous research to support the use of praise in classroom. Therefore, it is highly recommended that the use of praise should be a core element in teaching activities as it encourages and reinforces positive learning climate.

The second major finding from the data of this study revealed that ignorance has increased disruptive behaviour; thus, teachers are also recommended to re-evaluate the effectiveness of the 'ignorance' strategy.

Finally, teachers should do self-reflection on teaching strategies used in classroom as this would help teachers to improve their teaching quality. Teacher's ability to observe classroom situation and ways to respond to several types of misbehaviour are supposed to be part of the goals of professional education modules.

\section{REFERENCES}

[1] Lim, P. G. J. Pedagogical and Learning Strategies for Promoting Internet Information Literacy in Singapore Secondary School Students. International Journal of Pedagogies and Learning, 1(3), 2005, 30-43.

[2] James, A. R., \& Coolier, D. H.. Warm-Ups: The Key to the Beginning of a Great Lesson. Strategies, September/October, 2011, 1415 .

[3] Siwatu, K. O., Frazier, P., Osaghae, O. J., \& Starker, T. V. From Maybe I Can to Yes I Can: Developing Pre-service and In-service Teachers' Self-Efficacy to Teach African American Students. The Journal of Negro Education, 80(3), 2011, $209-222$.

[4] Allen, P., Taleni, L. T., \& Robertson, J. "In Order to Teach You, I Must Know You." The Pasifika Initiative: A Professional Development Project for Teachers. New Zealand Journal of Education Studies, 44(2), 2009, 47-62.

[5] Park, S., \& Oliver, J. S. Revisiting the Conceptualisation of Pedagogical Content Knowledge (PCK): PCK as a Conceptual Tool to Understand Teachers as Professionals. Research in Science Education, 38, 2008, 261-284.

[6] Shulman, L. S. Knowledge and Teaching: Foundations of the New Reform. Harvard Educational Review, 57(1), 1987, 1-22.

[7] Gottfredson, D. C., \& DiPietro, S. M. School Size, Social Capital, and Student Victimization. Sociology of Education, 84(1), 2011, 69-89.

[8] Daniels, M. L. The Three Fs of Classroom Management. Journal of Scholarship and Practice, 6(3), 2009, 18-24.

[9] Hue, M.-T. The Influence of Classic Chinese Philosophy of Confucianism, Taoism and Legalism on Classroom Discipline in Hong Kong Junior Secondary Schools. British Journal of Guidance and Counselling, 36(3), 2007, 303-316.

[10] Weiner, L. Why Is Classroom Management So Vexing to Urban Teachers? Theory Into Practice, 42(4), $2010305-312$.

[11] Martin, J., and Sugarman, J. Models of classroom management: Principles, applications and crtirical perspectives (Second ed.). (Washington: Detseling Enterprises Ltd, 1993).

[12] Ross, S. W., \& Horner, R. H. Bully Prevention in Positive Behaviour Support. Journal of Applied Behaviour Analysis, 42(4), 2009, 747-759.

[13] Filter, K.J., McKenna, M.K., Benedict, E.A., \& Horner, R.H. Check in/check out: A post-hoc evaluation of an efficient, secondarylevel targeted intervention for reducing problem behaviors in schools. Education and Treatment of Children, 30, 2007, 69-84.

[14] Dunlap, G., Carr, E. G., Horner, R. H., Zarcone, J. R., \& Schwartz, I. Positive Behaviour Support and Applied Behaviour Analysis: A Familial Alliance. Behaviour Modification, 32(5), 2008, 682-698.

[15] Fabiano, G. A., Pelham, W. E., Jr, Gnagy, E. M., Burrows-MacLean, Burrows-MacLean, L., Coles, E. K., et al. The Single and Combined Effects of Multiple Intensities of Behavior Modification and Methyphenidate for Children with Attention Deficit Hyperactivity Disorder in a Classroom Setting. School Psychology Review, 36(2), 2007, 195.

[16] Chitiyo, M., \& Wheeler, J. J. Challenges faced by school teachers in implementing positive behavior support in their school systems. Remedial and Special Education, 30(1), 2009, 58-63.

[17] Rogers, B. Behaviour Management: A whole-school Approach (2nd ed.). (London: Paul Chapman Publishing, 2007).

[18] Olweus, D. A profile of bullying at school. Educational Leadership, 60(6), 2003, 12-17.

[19] Beskeni, R. D., Yousuf, M. I., Awang, M. M., \& Ranjha, A. N. The Effect of Prior Knowledge in Understanding Chemistry Concepts by Senior Secondary School Students. International Journal of Academic Research, 3(2), 2011, 607-611.

[20] Awang, M. M. An Exploration of Strategies Used by Malaysian Secondary School Teachers to Promote Positive Behaviour: Professionals' and Pupils' Perspectives. Thesis, University of Dundee, Scotland, PhD, 2012.

[21] Smolnisky, S. Are we doing enough? A look at teachers struggling in the classroom. Thesis, George Fox University, United States, PhD, 2009.

[22] Nor, S. M., Hamzah, R., Samad, A. A., Bakar, K. A., Mohamed, O., Tarmizi, R. A., \& Salim, S. S. Struggling Students in Low Ability Grouped Classrooms: Standardized Assessments and the Uphill Battle. The International Journal of Learning, 14(7), 2007 922. 
[23] Nock, M. K., and Kurtz, S. M. S.. Direct behavioral observation in school settings: Bringing science to practice. Cognitive and Behavioral Practice, 12(12), 2007, 2005, 359-370.

[24] Gotzens, C., Badia, M., Genovard, C., \& Dezcallar, T. A Comparative Study of the Seriousness Attributed to Disruptive Classroom Behaviours. Electronic Journal of Research in Educational Psychology, 8(1), 2010, 33-58.

[25] Nelson, J. A. P., Young, B. J., Young, E. L., \& Cox, G. Using Teacher-written Praise Notes to Promote a Positive Environment in a Middle School. Preventing School Failure, 54(2), 2010, 119-125.

[26] Wheatley, R. K., West, R. P., Charlton, C. T., Sanders, R. B., \& Taylor, T. G. S. M. J. Improving behaviour through differential reinforcement: A praise note system for elementary school students. Education and Treatment of Children, 32(4), 2009, 551-557. 